\title{
The Common Model of an Enterprise's Value Objects, Presented in Relevant Business Views
}

\author{
Jan Gustafsson $^{1}$ and Jarl Höglund ${ }^{2}$ \\ ${ }^{1}$ Ferrologic Enterprise Design AB, Stora Nygatan 14, 11127 Stockholm, Sweden \\ jan.gustafssoneferrologic.se \\ ${ }^{2}$ ALLMENTOR AB, Storsvängen 66, 12943 Hägersten, Sweden \\ jarl.hoglund@allmentor.se
}

\begin{abstract}
The purpose of the paper is to report on the experiences from four linked product structuring cases at large Swedish companies involving substantial concept modeling. Case by case will be described in brief, and we will discuss how the experiences from previous case add to the next. The main issues have been: one business view of the product dominates information access, the terminology and communication. We will discuss the value of having one common product model and unified terminology that is accepted in all processes adding value to the product. The modeling method will be discussed, including the way of working when many contributors must be on the arena. The paper analyzes the fact that what is supposed to be very company/product unique objects/relations, in fact often are generic. The most recent case introduces context as an object into an already complex product structure.
\end{abstract}

Keywords: Product, perspectives, participation, value objects, context, complete value chain, generics, complexity, resistance.

\section{Introduction}

The journey we have experienced started in a crucial phase at the to-be analysis of a product management process in a global telecom industrial environment. The purpose of the process is to control and maximize the product profitability over the complete life-cycle, considering three areas of responsibility- market needs, product characteristics and business control. That, in fact, implies interfaces to all other main processes and stakeholders in both the time-to-market flow and the time-to-customer flow, and their specific views on the product.

Our objective in the project was to find out if there were some commonalities in how the product was structured, and if people communicated using the same terminology regarding the product, and other product related terms, and to identify points of measurement. The initial as-is study gave us the immediate answer that this was not the case.

The main question was: What is the "product"? To some parts of the enterprise it is only what is sold and delivered. To other parts it is something else. Subsequently it is very important to regard the product as the value-carrying object throughout the 
enterprise. This means it includes the sold product, the parts it consists of, included functions, configured models, etc. Actually it includes all objects that time, money or effort is spent on, or that generates money, or the investment object. This also means that the "product" exists as a value-carrying object long before it is developed or produced, and in fact, as soon as someone spends working time thinking about it.

At this time we got an inquiry from the CFO: What does the company make money on? Which products are profitable? Suddenly we had a sponsor to at least start an analysis of how to structure the product to please all stakeholders.

The method for all coming cases, represented by this "meta case" is Conceptual Modeling, based on the Entity-Relation modeling principles [2].

We know that the method is a pre-requisite, but not the only key to success. The key is rather how we have applied the method to the identified situation, and the outcome [Astrakan reference here].

The first issue is to have a clear and common understanding about and difference between "concepts and terms" [3].

It is also important to realize and accept that everything may be looked at from different viewpoints, and may have different meaning to different viewers. All views are correct, and relevant, but to different viewers in different situations, or business functions. In this case it is important not to confuse the organizational division of the enterprise with the functional views. A functional view gathers all parts/roles that regard a common "thing" in the same way. The thing being the "product" as defined earlier, as a value-carrying object.

In order to visualize this and to make it pedagogical, we used the metaphor of a flower. The petals of the flower each represent a business functional view of a shared/common object in the centre of the flower, the seed-pod.

The business views most likely like to see the information sorted in some sort of structure of the product, and mostly in a hierarchical way, suitable for their view. The different views have a need for different sorting, and thereby different hierarchical structures. In order to produce theses different structures without storing information more than once, it is essential to build a logical model of information objects and business rules in the centre of the flower, the seed-pod. The logic of the central model may the present information in different hierarchical context, to different business views.
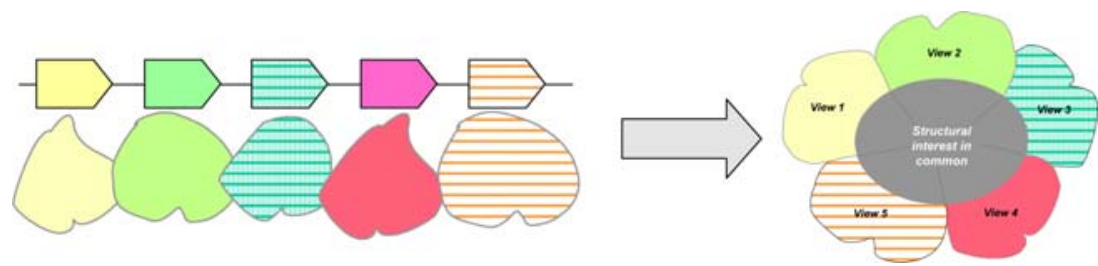

Fig. 1. Each process/business function, and their views on the product 
When modeling the "product" of an enterprise it is essential to model on appropriate abstraction level. This means to focus on the concepts rather than the information. The concepts are the objects/information holders and the "thing" you want to know something about. The information is attributes of the concepts, initially utilized to identify the correct concepts and their inter-relational logic.

Another extremely important issue is to define the relevant projection of the effort. Projection is to set the scope for the model according to the mission of your business, the business idea.

An example of projection -- for a producer of speed boats the boats are their products, being the result of their efforts. So is the hull, the keel and the deck. Even if their products are "things", not all "things" are products to them. They use drills, grinders and lathes when producing their products, but these are not products to their business. They are means/tools.

To the company producing tools, they are products, of course. That is a different projection. The reason is to ensure that the content will be the "product" in the sense of value-carriers, not assets in general.

\subsection{Work Procedure for the Effort}

The analysis was performed in a number of workshops, starting with identifying the business views by the means of Stakeholders Diagram Analysis. This workshop was conducted together with representatives of the stakeholders, in order to cover the enterprise in a rational way.

After deciding the accepted business views (by management based on a recommendation from the participating stakeholders), the planning of one workshop per business view (petal of the flower) was initiated.

In each workshop, the participants were asked to focus on finding concepts/products that they use when communicating with other business views. In other words the participants were instructed to focus on finding the concepts/products that would be their "candidates" for the core model (the seed-pod of the flower). Objects and information that are proprietary to the view, is of less interest in order to define the common object model of product information.

After modeling all business views, a number (4-5) of candidates to become the common object model existed.

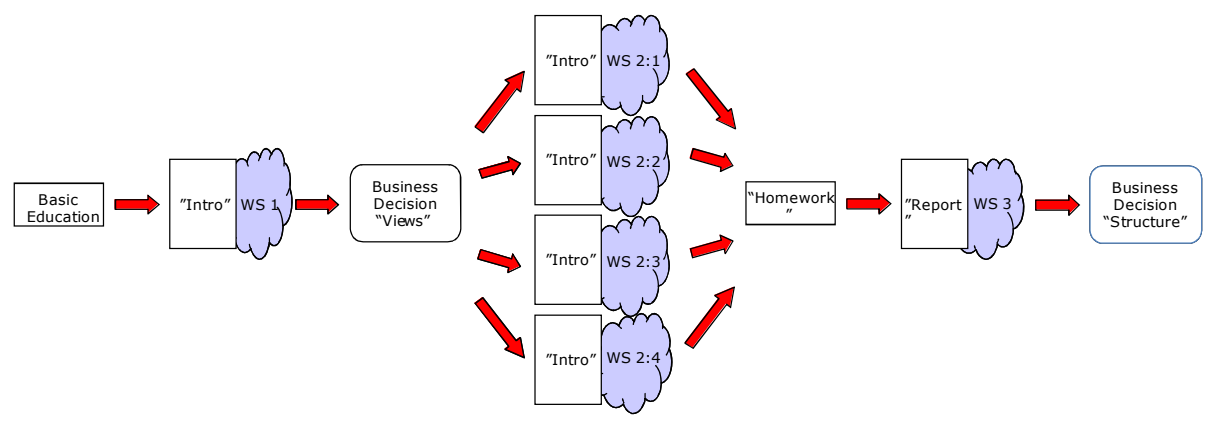

Fig. 2. Work procedure for the modeling effort 
At this stage in the procedure, the facilitators (us) had some homework to do. All the different versions/candidates to become the core model had to be analyzed, both separately and together. All concepts/products that existed in more than one view, had to be represented in the final core model.

After concluding "our homework" it was presented to the final workshop with representatives from all business views for final "massaging", leading to the concluded core model that was accepted by a management decision.

\subsection{Organization of the Paper}

The remainder of the paper is organized as follows. In section 2 there is a presentation of the cases, the reason for conducting them and the remaining results. In section 3 we summarize the experiences from the cases and the advantages in conducting this work procedure. In section 4 we make some concluding remarks and discuss issues for future work.

\section{The Cases}

There is no single case. We are now sharing our experiences from four selected cases. It is the sum of experiences from four different assignments that is evolving this way of performing modeling. The motivations for the different cases are specific, not the same, yet leading to the same need for analysis, of the "product model logic".

The cases that we summarize in our meta-case are from three different branches of business:

- Case 1 - A large manufacturer within telecom

- Case 2 - A portal business start-up during the dot-com era

- Case 3 - A large manufacturer of vehicles (corporate core)

- Case 4 - A large manufacturer of vehicles (service market's view of corporate core)

They all aim to run a profitable business, offering something that attracts the chosen marketplace, while producing and delivering it with a fair margin.

\subsection{Case 1 - Matching Revenue to Cost of the Products}

The controller of one company stated a question to the managers of the different business units - "Last year we had a very good result within the company. Which products created that result?" The managers had to assemble the information, and get back to the controller, but their reply was "We don't know. We have no idea!" The controller replied "Lucky for you that we had a good result!"

At this time we belonged to a team responsible to map and establish the product management process at the company, and the controller asked us for help - "I need a way to be able to match cost, and investments to the revenue of a product!" Since we regarded this as a core issue within product management, we responded that we would gladly take on this assignment. 
At this time the revenue of each "order" was registered under one of hundred "product codes". There was also one product code named "other", where about $80 \%$ of all orders were booked! The controller asked if we could help him to reduce the number of "product codes", to less than ten, just to make it manageable. We responded with a desire to map the product, as a value-object through-out the entire business, from each applicable business perspective. This implied making a conceptual core model of "product".

The controller gave us "carte blanche" as long as we reduced the number of "product codes" within three months.

We realized that the enterprise had a premium product data management system support for the existing product structures. However, the structures represented the development view of the products. This was perfect for designers, but less suitable for sales and production staff. We defined the need for the business to look at the "product" from different view-points, depending on the business view.

The modeling job was performed according to the work procedure described earlier, with the metaphor of the flower with business views sharing a common product core model.

In a first workshop, where a variety of business functions, derived from the main process map, were represented we analyzed that five different perspectives of the product, would cover the desired control. The views were: Product Management, Marketing \& Sales, Supply, Development and Operation \& Maintenance.

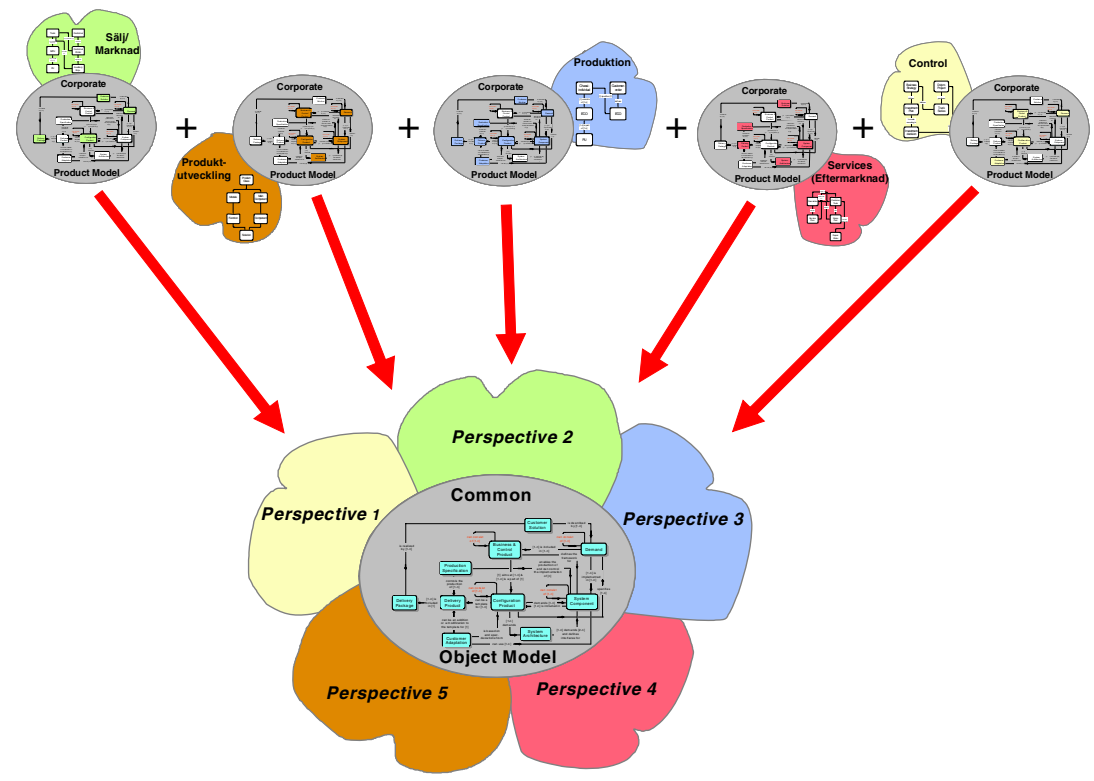

Fig. 3. The flower as a metaphor, and the work procedure for developing the common object model 
We had realized that the different views had to see different, or the same, information of the products, but placed in different contexts. We also realized that we had to find some common "core logic" that kept the information and products in some sort of order, so information could be generated into structures suitable for the different business views need of product information.

This was actually the first time we utilized the metaphor with the flower to the full extent.

In order to find the logic of the common object model that would fulfill the needs of each business view, we decided to model with the representatives from each view separately. The reason for that was to prevent arguments between people representing different views to arise at this early stage, and the problems to facilitate the number of representatives needed in only one big workshop.

The instruction to the workshops in each view, was to ask them: regarding which product objects are you sharing information with other business views?

Our finding was also that people in the business are quite used to model their business, but mostly in terms of processes and activities. The change in focus was to concentrate on the prerequisites for a specific task, as input, and the result, as an output, finding and modeling the product, as the "back-bone" value carrier in the business flow.

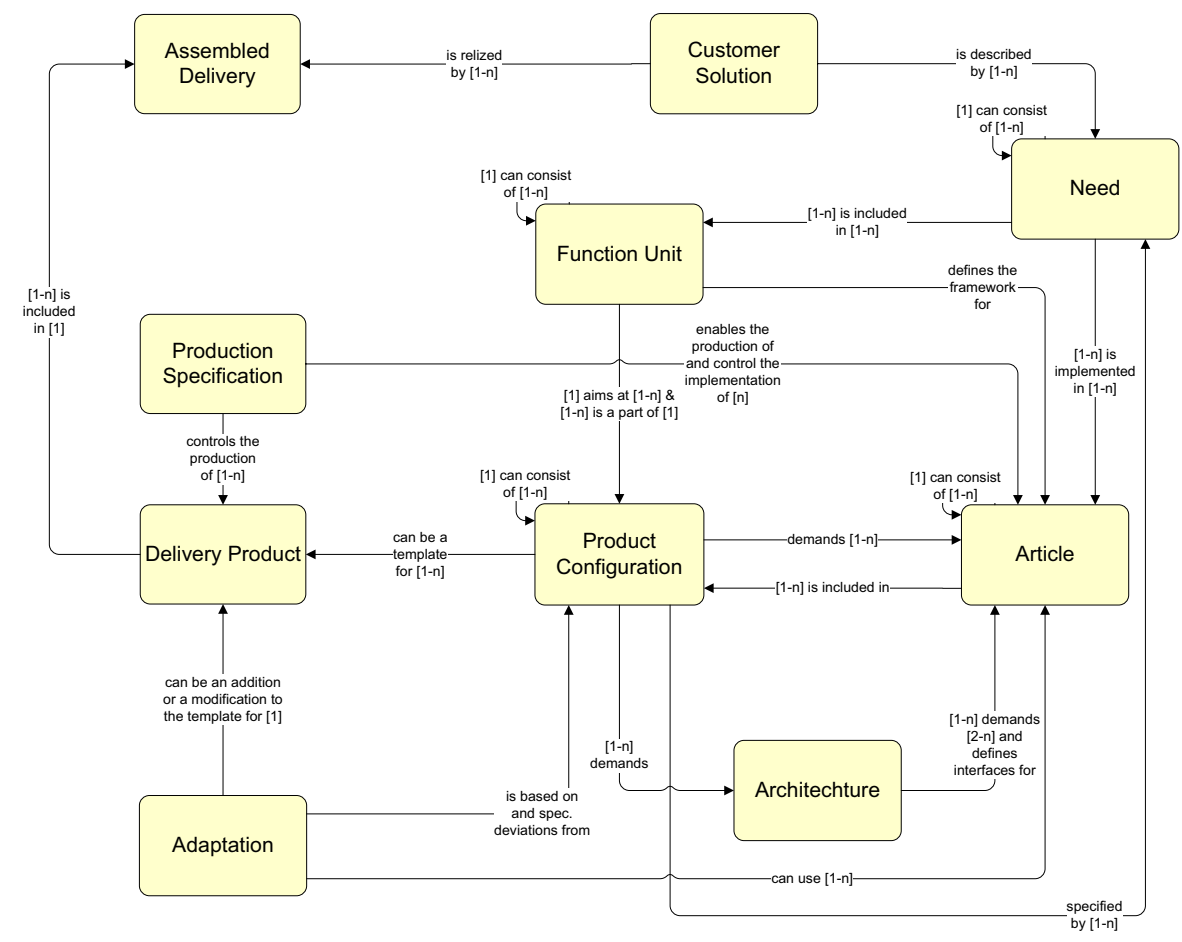

Fig. 4. The common object model of the product 


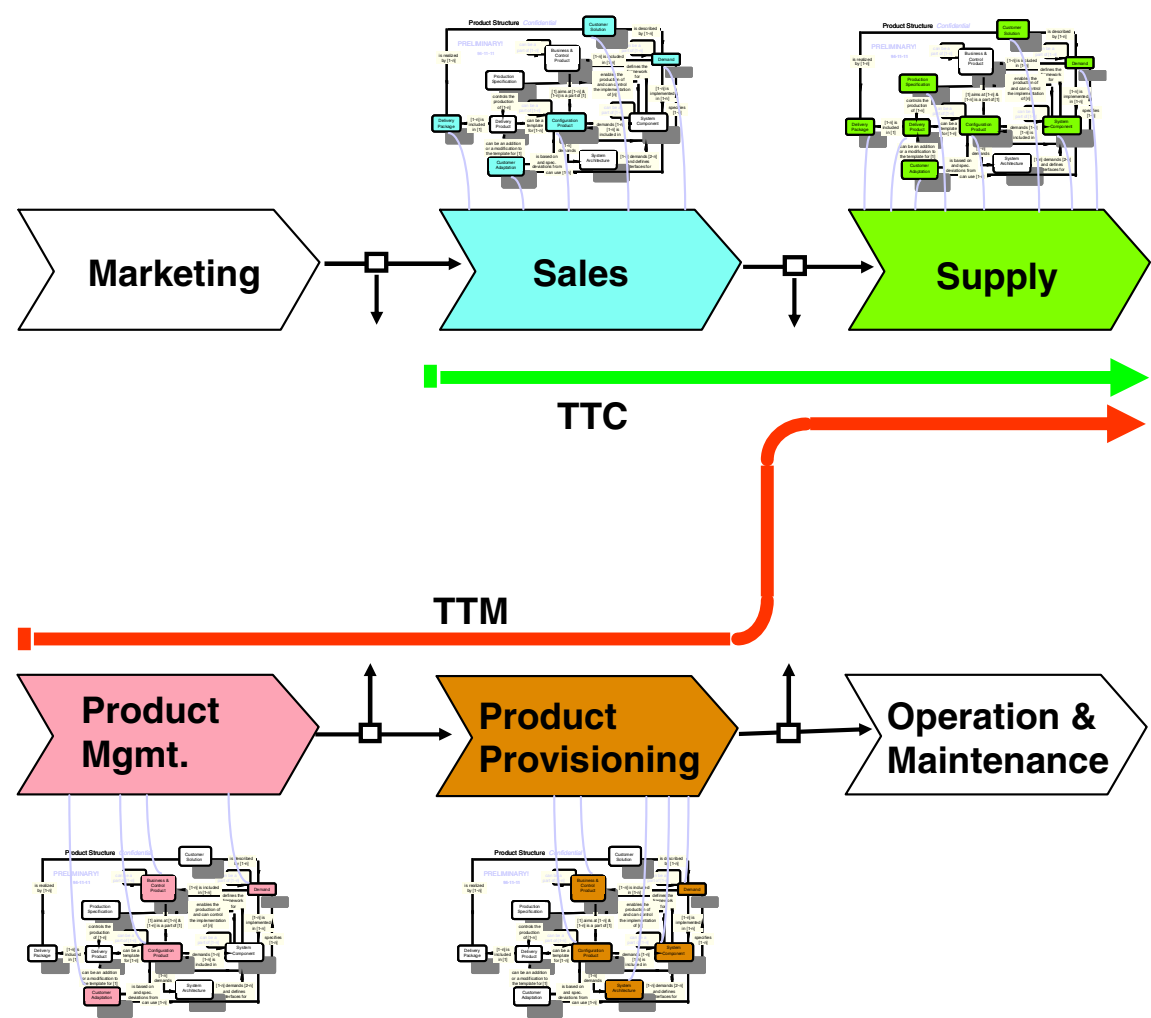

Fig. 5. The different petals of the flower metaphor, laid out in the product flow at the company

After having results from each and every business view, in this case five, we would stack them on top of each other, and "x-ray" the stack, in order to find commonalities, and differences. Everything that existed in two or more business views was selected as a candidate to be a core object. In this normalization effort, performed in a workshop with a few representatives from each previous view workshops, we created the logical pattern with all core objects (shared by at least two business views).

\subsection{Case 2 - A Portal Business Start-Up during the Dot-Com Era}

A start-up company had found a niche on the internet market, where a portal could be positioned in order to orchestrate a bonus redemption program for a number of underlaying e-business retail portals (e-biz partners).

Our assignment was to "categorize the product" to enable, the business idea. We realized that the way to go was to analyze and model the product in a corporate core model in order to present it in several appropriate views. The problem however was that categorization is much like sorting something into different boxes -- fine for one situation at one particular moment in time. But different viewers may want to see the things sorted in different ways for different situations. And the things may only be placed in one box at a time... 
The business idea was to identify a certain product that was sold to a customer on internet, by one or possibly several members. Except for the needed possibility to identify a particular sold item regardless of retailer within the "portal". Additionally the idea was to analyze the customer's combination of purchased items (customer's shopping cart) and recommend what to buy next. In this "portal sphere" there would also be providers of content (advertisers, editors, etc.) as well as providers of the bonus rewards. A part of the financing of the business would also be based on advertising. The company for this "top portal endeavor" was based on venture capital and two persons to administer the portal (run the business).

We started by analyzing the vision, mission, goals and strategy defined for the business. We also identified the "e-biz partners" being the e-business portals to be connected to the bonus/redemption program. In parallel with our investigation to "categorize the product", another part of the project had already started to build the "redemption engine", the solution that would keep track of all products, customers, retailers, purchase transactions, bonus accounts as well as realized and pending redemptions.

Again we utilized the work procedure that we presented in the introduction - identifying business views, modeling workshops per business view, conducting normalization homework, and finalizing the core model.

The views were defined as Business Control, Member Services, Individual visitor and/or member, E-biz Partner, Space Customer, Advertisers, Media Brokers and Provider of Content, Public Services and Rewards.

In this case we experienced something new - since this was a start-up, the business staff to involve in the modeling workshops did not exist. The modeling per view had to be simulated as homework. We had to interview the two founders in order to understand their intension with the business, and thereby simulate the business-to-be, in workshops "at home". We also interviewed companies (e-biz partners) from each view about the forthcoming business set-up. The core model was created from all the business views and their need to control and benefit from the business.

The basis of the idea to map, log and analyze the demographic patterns of purchases, as well as common product portfolio among a number of retailers, was found to be very hard, if not impossible, due to the fact that products did not have unique identifiers. For example, a specific sports shoe from one retailer was called "gymnastics shoe" from another, and "tennis shoe" from a third. The only product that was possible to handle, within the specified portfolio, was books based on the ISBN global numbering standard.

It also became quite obvious that this would not become a "pianola" for the two founders. The interaction to administer this logical core was to become enormous.

The effort to run this portal enterprise was very demanding. The founders realized this, after being presented to the facts and the whole business idea was changed. Instead of actually running this "portal sphere" for bonuses and redemption, they would capitalize on the developed solution by making a product of that and selling it to other companies to run a redemption scheme. 


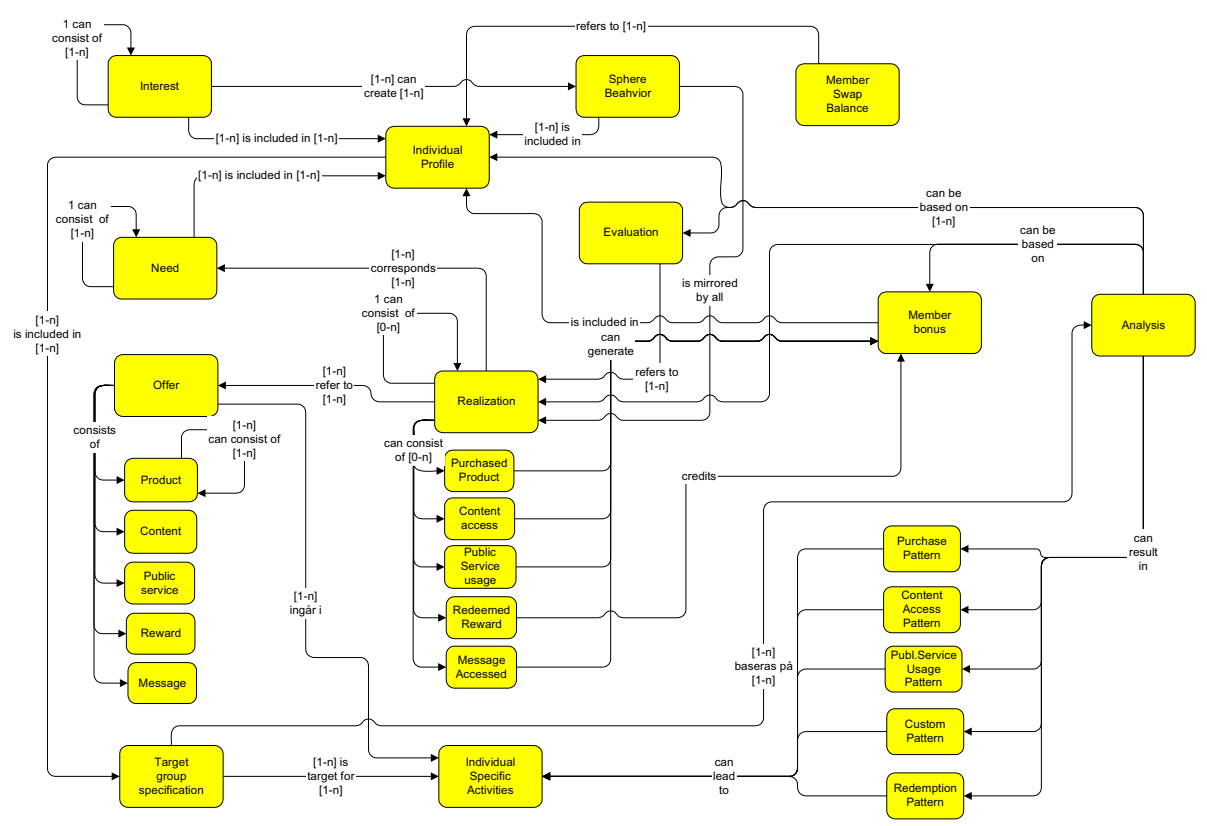

Fig. 6. The common object model of the product for the portal enterprise

\subsection{Case 3 - A Large Manufacturer of Vehicles (Common Object Model)}

Case 3 took place at an industrial company that is well known to the market, as being very efficient in utilizing few parts combined in many configured products.

The reason to re-investigate how this is handled is due to the fact that the principles for re-use and modularity have been practiced within the company since the 1950s, but applied to mechanical products. Mechanics can be perceived as easy to understand due to the visibility. During the last few decades there has been an increasing involvement of electronics, and recently also computers and software. The existence of these things is not as obvious, due to the lack of physical presence. Additionally the new technology brought in new terminology, such as, for instance, "system".

A system was now considered to be a logical context, which utilized components to fulfill a desired function/service for electronics and software.

It is worth pointing out that a vehicle has had a lot of "systems" historically, but they are mechanical such as exhaust, steering, brake, propulsion, etc.

The new technologies, like electronics and SW, have brought in a capability to meet new needs and fulfill new functions in a completely new way of realizing it. That has led to an exponential increase in number of functions on a vehicle, and thereby the complexity is increasing continuously.

The company has early on, at least earlier than others, realized the need to have different structures for different business views. The fact to let the two perspectives for development and production interact, has placed the company far ahead of their competitors. 


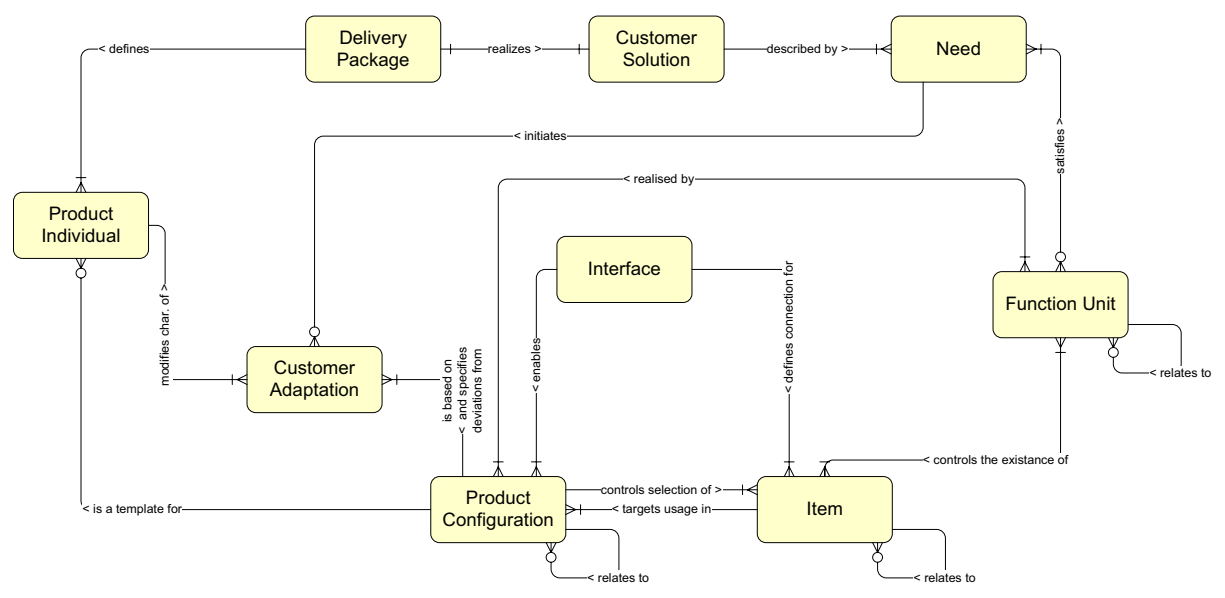

Fig. 7. The central common object model of the product

The stakeholders diagram was defined to the following views, or perspectives as this company decided to call them: Sales \& Marketing, Production, and Service Market, Research \& Development, and Control. We also decided to call the evolving common object model the "Corporate Product Model".

The greatest interest and largest need to achieve a better support to the business was from Service Market. So we decided to start with that business view. The workshops would be run in the backward order of the product life-cycle: Service Market, Production, Sales \& Marketing and Research \& Development. The last perspective Control was handled through project interwork between the development and marketing functions. The common object logic induced by "control" was however captured.

During the project we observed the low level of tool support that was addressed to Service Market and to Sales/Marketing. The production organization is used to handle total mass-customization and have accepted that all vehicles are unique and different. No commonality, no models and no patterns are of interest. Models are however essential for any sales effort since the buyers would identify models based on utilization. Within Service Market it is also of interest to see/utilize models or similar abstractions of commonality, in order to prepare service workshops with repair manuals for typical product configurations (models).

When assembling the common object model we found "clusters of information" without any obvious concept/object to hold it. We also found same or similar "clusters" in many /all business views. Obviously we had discovered a well known, but undefined object that was extremely central to the business. The object was the Product Configuration which is central object to all perspectives. It has six relations to other objects in the common object model, as well as it has it's own multiple structures.

This led us to the fact that when the final presentation of the result was made to the main stakeholders, as well as most of the involved persons from all workshops, everyone involved said: "That's our model!". None of the workshops had seen the final model, but they could all relate to the final result to come. 
A notable difference between the common object model in Case 1 and Case 3 is that the relations "can consist of" has been replaced by "relates to" for the configuration. This means that the structural need differ between the business views, and one single structure in the common object model, would be wrong. (See Case 4).

\subsection{Case 4 - A Large Manufacturer of Vehicles (Service Market View of Corporate Common Object Model)}

After the effort to map and create the business logic on corporate level, supporting all business perspectives, there was a direct interest from some views to proceed with the next level of business analysis.

The service market was in a troublesome situation, due to the fact that they are not only working with the latest products and their information, but are also forced to handle information for the product during 5-10 years to come.

Within the Service Market perspective an assignment was defined, in order to analyze the as-is and the to-be situation for Service Market specifically.

The staff within service market has to define and maintain information for products and parts that exist on the market. One of the objects identified during the modeling of the common object model (Case 3) is the Product Configuration. That is one of the few objects that is regarded/seen from all views. It was concluded earlier that the relations of that object differed between the views, and even how the recursive relations would be applied. A very interesting finding in this perspective is that product configurations have to be presented having a hierarchical structure that is unique to Service Market, and has to have a different structures presented to other perspectives.

The solution was when we realized that Product Configurations had a structure based on "Components" playing a role in a specific "Context". This means that the context does not "own" the component, as it would in a traditional hierarchy, but instead is "utilizing" it.

One component may subsequently play a role in several contexts. It also became very obvious that the component is not equal to a physical item. The component is the logical "space" or "position" defined by the context. The item can play the role as a component in a context.

Another notable finding is that there are two different break-down structures important to Service Market: logical and physical. Physical is important to find the need

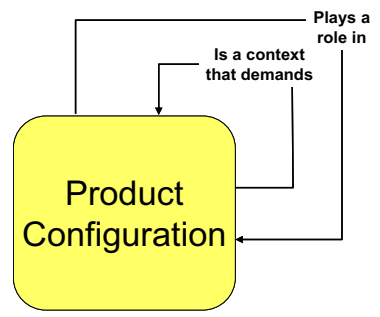

Fig. 8. The recursive Product Configuration 
for specific spare parts, and logical is crucial for analyzing faults and errors in the functionality of the final product.

This also calls for the need to keep information on abstract object level (product without instances) in an applied logical structure. Information that would need this level is for instance "system". A system is a logical context, which may be applied physically different, on different instances of a product, thus having the exact same function and characteristics regardless of implementation.

The culture of this company is to re-use few parts in different contexts, creating modularity. Therefore no hierarchical structures may be stored for re-use, thus needed to be utilized with different sorting, depending of purpose.

In the view for service market a component is to be regarded as a role in a logical context. A part/item may take that role, or several roles in different contexts.

On the contrary, within production a "component" may be a role in a "physical" context, being parts at the assembly line.

\section{Experiences}

Our experiences from the four product structuring cases have been as a relay race, each case has added value to the next etc. The predominant experience is probably the break-through in Case \#4 where the principle of roles in contexts was introduced.

\subsection{Deliverables Case \#1}

The prime assignment was to architect the future product management process, and an additional request from the CFO was to find a way to reduce the number of product codes (class of goods). The result ended up in a reduction of the number of product codes from more than 100 to less than 10. Revenue could now be tied to chosen level in the structure of business control products (see fig 4), enabling monitoring of product profitability. Furthermore the establishment of product configuration as a key central object paved the way for a potential efficiency increase in all processes from sales to delivery in the range of $50 \%$.

\subsection{Deliverable Case \#2}

The assignment was to set a model to qualify and further specify a completely new business model on the dot.com arena. The result ended up in a new strategy. Instead of actually running the portal sphere for bonuses and redemption, the strategy became to capitalize on the developed solution, by making it a product and sell it to other companies to run redemption schemes.

\subsection{Deliverable Case \#3}

The assignment was to map all key stakeholders view of the product, in addition to enabling phase-out of the current IT platform for product data management.

The resulting core product model, explicitly illustrated the importance of controlling complex product configurations in order to reuse information regarding the configuration of the delivered product, not only in development and production, but also 
in sales and the long lasting and profitable service market. This created a new basis for enhancement of efficiency in terms of lead time and quality, as well as basis for IT requirements on future product data support. The service market representatives in the assignment realized there potential value and initiated the next case.

\subsection{Deliverable Case \#4}

The assignment was to utilize the common object model developed in case \#3, in order to find and detail the product structure tailored to service market's needs. Configuration objects to "hang" information on, was needed in order to keep structure information to supply spare parts, create and maintain repair instructions, and functional instructions for service workshops.

The key result was to allow unique structures to exist for the use of service market, respecting similarities between delivered products (models), even-though all delivered product unique by the means of mass-customization in production. The structures in the service market view are not a base to store information, but to generate and present from the common object model.

\section{Conclusions and Future Work}

It has been a very awarding journey to go through all these four cases, in different business environments, which has created an enormous increase in insight, while we have been having a real good time!

The metaphor of the flower is a prerequisite for success. The same object may be seen from different view-points, both demanding attribute filtering, as well as seeing an object in relation to different surroundings (other objects), depending on the purpose of that view-point.

Essential to all the efforts of conceptual modeling is to be really precise in delimiting the scope of the domain to model.

A key insight from Case \#1 was to find the configuration product being a value carrier in the whole enterprise. That was the last object to appear in the model, thus being the most central, with the most number of relations to other object, as well as being regarded from all business views. The object appeared by the gathering, or a cluster, of information with no object to "hang it" on. Key insights from Case \#2 - the common object model was proved to be useful even in a non industrial environment. It is more generic than we initially realized. If the "product" was regarded, not only as a physical thing, but as anything in an enterprise being the result of effort and carrying value, it really became an eye-opener to us all.

Key insights from Case \#3 - this time we were addressing an enterprise that already has done this effort, leading to combination of two business views. The challenge was now to first address an addition/shift in technology. All structural work previously performed, was related to mechanical products. Now the business is adding electronics and software which was less tangible.

Adding two more business views also proved the fact that the imbedded structure in our previous core model no longer could remain hierarchical. "Consists of" was 
replaced by "relates to". The reason for that is that "structure" was handled as a synonym to hierarchical. The structures had to be different in the different business views. Therefore the information origin in the common object model had to be nonhierarchical and the stricter had to be generated on demand.

Key insights from Case \#4 - the imperative finding in this effort was that there may be needs to have multiple break-down structures of the same product configuration, depending of utilization. Role and "Context" becomes obviously crucial in order to create the necessary logic in the common object model. There must be both a logical and physical breakdown of the delivered product in order to navigate and coordinate the information.

The following insights come from all cases:

- The applied approach, e.g. to be very focused on the WHAT-perspective and its structures, after the analysis of WHY and HOW, have been part of the success in all cases [1].

- The access to a sponsor, with driving spirit in the management team is a prerequisite in order to get competent people to the analyses and to reach out with the result and obtain the expected effect. In one case we did not have a supporting sponsor, and that made it much harder to proceed as planned. This is in line with the recommendation in [4] of acquiring the management support which helps securing authority and resources for the modeling project.

- The chosen order in running workshops by view was according to reversed product lifecycle, i.e. services first and end with product development. The project should begin with one workshop per chosen view. In this way the stakeholders become confident with their "structures" before we start to find the common object model content. By doing so we got less irrelevant and time consuming discussions.

- The missing object, which "always" appears in the centre of the structure model, came in place as we have a way to identify it. By testing alternatives, and listen to the spoken language we are able to find it. To ask the question "why" and "to be used as", usually gives the answer. Experienced facilitators are needed.

- The importance of communication, both during the analysis in order to obtain quality and participation, as well as when reporting the outcome, e.g. never presenting the whole structure at once, making an animated presentation so the complexity can be digested in logical portions, etc.

- The common object model must not inherit any hierarchical structures of any kind, since they lock the information in a specific context. The model shall instead contain the "atomic" information and necessary logic represented by business rules, to enable generation of information in hierarchical to the proper business perspectives.

We think there are interesting areas for further research, such as:

- We realize again and again that "unique" structures and processes/value chains in fact are generic. To what extent can we know/assume what's unique or generic?

- How to calculate/illustrate/argue the potential business value in having the common structure of products/services/offerings? 


\section{References}

[1] Astrakan Method, http: / /www.astrakan.se

[2] Chen, P.P.S.: The Entity Relationship Model - Towards an Unified View of Data. ACM Transactions of Database Systems 1(1) (1976)

[3] Ogdens Triangle, http: / / www. ogden.com

[4] Stirna, J., Persson, A., Sandkuhl, K.: Participative Enterprise Modeling: Experiences and Recommendations. In: Krogstie, J., Opdahl, A.L., Sindre, G. (eds.) CAiSE 2007 and WES 2007. LNCS, vol. 4495, pp. 546-560. Springer, Heidelberg (2007) 